\title{
PRODUÇÃO IN VITRO DE EMBRIÕES BOVINOS COM SORO DE ÉGUA EM DIFERENTES FASES DO ESTRO
}

\author{
IN VITRO PRODUCTION OF BOVINE EMBRYOS WITH MARE'S SERUM \\ FROM DIFFERENT MOMENTS DURING OESTRUS
}

\begin{abstract}
GIULIANO MORAES FIGUEIRÓ MARTA PASIN ${ }^{1}$, LUCIO PEREIRA RAUBER ${ }^{1}$, MARI LOURDES BERNARDI ${ }^{2}$, ALCEU MEZZALIRA ${ }^{3}$, MARA IOLANDA BATISTELLA RUBIN ${ }^{4}$ \& CARLOS ANTONIO MONDINO SILVA ${ }^{4}$
\end{abstract}

RESUMO

A produção in vitro de embriões (PIV) bovinos é atrativa pelo baixo custo de produção, uso na clonagem de células somáticas e embriões, produção de vacas transgênicas e na pesquisa básica. As proteínas acrescidas aos meios de cultivo parecem ser um dos principais fatores limitantes nas diferentes fases da produção, e são representadas, em primeira instância, por materiais de origem biológica que fornecem aos embriões nutrientes e outros fatores pouco conhecidos. Este trabalho avaliou o uso do soro de égua, obtido em diferentes fase do estro na PIV. Complexos cumulus-oócitos (CCO) obtidos de ovários bovinos em matadouro foram maturados por 22-24h, em estufa $\left(5 \%\right.$ de $\mathrm{CO}_{2}$, umidade saturada e $\left.39^{\circ} \mathrm{C}\right)$ em TCM-199 $+\mathrm{HEPES}+\mathrm{LHb}+\mathrm{rFSHh}$ com $10 \%$ de soro de égua coletado no primeiro dia de estro (T1), 24-48h antes da ovulação (T2) e 24-48h pós-ovulação (T3), servindo como controle (C) o mesmo meio com soro de vaca em estro. Os CCO foram fecundados em TALP-FERT sob as mesmas condições e cultivados em fluido sintético de oviduto $(\mathrm{SOF})+5 \%$ do soro dos T1, T2, T3 ou C, por 8 dias, sob óleo mineral. A taxa de clivagem foi similar entre os tratamentos. A produção de blastocistos no D7 nos tratamentos $(\mathrm{T} 1=21 \%, \mathrm{~T} 2=21 \% \mathrm{e}$ $\mathrm{T} 3=20 \%)$ foi maior $(\mathrm{P}<0,05)$ que no controle $(12 \%)$. A taxa de eclosão no T1 $(9,8 \%-47 / 477)$ foi maior $(\mathrm{P}<0,05)$ que no T2 (3,1\%-15/477), T3 (4,2\%-21/505) e Controle (4,1\%-20/486). Os blastocistos eclodidos do T3 apresentaram menor $(\mathrm{P}<0,05)$ número de células no $\mathrm{T} 1 \mathrm{e}$ Controle. As taxas de blastocistos em D7 com o soro eqüino foram superiores às obtidas com soro de vaca em estro. Para evitar transmissão de doenças espécie-específicas, recomenda-se o uso do soro de égua em estro para a produção in vitro de embriões bovinos.

Descritores: embriões, bovinos, PIV, soro de égua, soro heterólogo.

\section{ABSTRACT}

In vitro embryo production (IVP) is an attractive technique because of the low-cost production of numerous bovine embryos, use in somatic cell and embryo cloning, production of transgenic cows, as well as for basic research. Protein in the culture media appeared to be one of the most significant limiting factors in the different steps of this technology. These protein sources are represented mostly by biological materials which provide nutrients and other poorly understood factors for the embryos. This study evaluated the possibility of using mare's serum obtained at different stages during oestrus for bovine in vitro production. Complexes cumulus-oocytes (CCO) from slaughtered cows ovaries were matured in a controlled incubator $\left(39^{\circ} \mathrm{C}, 5 \% \mathrm{CO}_{2}\right.$, saturated humidity) for 22-24h in TCM-199+ HEPES + bLH + $\mathrm{hFSHr}+10 \%$ mare serum collected at the $1^{\text {st }}$ day of oestrus (T1), 24-48h before ovulation (T2) and 24-48h after ovulation (T3) and a control group (C), using the same medium added $10 \%$ oestrus cow serum. In vitro fertilization (IVF) was performed in TALP-FERT under the same conditions and in vitro culture (IVC) on synthetic oviduct fluid (SOF) $+5 \%$ of T1, T2, $\mathrm{T} 3$ or $\mathrm{C}$ serum, during 8 days under mineral oil. Cleavage rates were similar between treatments. Blastocyst rates at D7 were higher $(\mathrm{T} 1=21 \%, \mathrm{~T} 2=21 \%$ and $\mathrm{T} 3=20 \% ; \mathrm{P}<0.05)$ than the controls $(12 \%)$. Hatching rates in T1 $(9,8 \%-47 / 477)$ were higher $(\mathrm{P}<0.05)$ than T2 (3.1\%-15/477), T3 (4.2\%-21/505) and C (4.1\%20/486). Hatched blastocysts of T3 had a lower $(\mathrm{P}<0.05)$ number of cells than those of T1 and Control. Considering it's heterologous nature, the possibility of preventing disease transmission and the higher blastocyst rates at D7 reported here, the use of oestrus mare's serum can be used for the IVP of bovine embryos.

Key words: embryo, bovine IVP, mare serum, heterologous serum. de Zootecnia da Faculdade de Agronomia - UFRGS, Porto Alegre - RS. ${ }^{3}$ Laboratório de Reprodução Animal do CAV - UDESC, Lages - SC. ${ }^{4}$ Laboratório de Embriologia e Reprodução Animal do DCGA / CCR - UFSM, Santa Maria - RS. [www.ufsm.br/embryolab].

CORRESPONDÊNCIA : G.M. Figueiró [e-mail: moraesg@terra.com.br ; FAX: + 55220 8501]. Av. Estudante José Júlio de Souza, 980/703. C.E.P. 29102-010, Vila Velha, ES - Brasil. 


\section{INTRODUÇÃO}

Os primeiros estudos sobre fecundação in vitro em bovinos iniciaram na década de 60 , com a produção do primeiro blastocisto em 1968 [37,38]. Em 1987 foi divulgada a primeira prenhez produzida por um processo totalmente in vitro [25], gerando no ano seguinte o nascimento de gêmeos [26].

Desde então, os estudos sobre a produção in vitro (PIV) de embriões bovinos foram desenvolvidos em busca de um protocolo definido, isto é, um meio com composição definida sem fonte protéica de origem animal, que reduziria a grande variabilidade entre as taxas de produção de embriões nos laboratórios. Os protocolos desenvolvidos com meios definidos ainda não apresentam taxas de PIV de embriões que se equiparem às taxas obtidas com protocolos cujos meios utilizados contêm soro $[16,19,27,32,43]$.

O soro heterólogo, principalmente o soro fetal bovino, é utilizado na produção in vitro (PIV) de embriões nas diferentes espécies animais $[9,17,24,33,46]$. A adição do soro eqüino na PIV de embriões bovinos baseia-se nos excelentes resultados obtidos por Mezzalira [28-30] com embriões de camundongos em estágios iniciais, cultivados em meios com soro eqüino, no final da década de 80 .

$\mathrm{O}$ uso de soro de égua poderia ser uma alternativa para evitar a transmissão de doenças espécie-específicas que podem ser carreadas pelos diferentes materiais de origem protéica, fontes potenciais de patógenos. Além disto, apresenta como vantagem a facilidade de obtenção de grande quantidade de soro numa única coleta, quando comparado com a obtenção de soro bovino.

Este experimento teve como objetivo avaliar o uso do soro de égua obtido em diferentes fase do estro na produção in vitro de embriões bovinos.

\section{MATERIAIS E MÉTODOS}

\section{Obtenção do soro}

O soro foi obtido de 9 éguas com sanidade comprovada, sendo coletado durante três etapas distintas do estro. O sangue foi coletado em tubos de ensaio com vácuo, através da punção da veia jugular, sendo o mesmo mantido até a retração do coágulo, à temperatura ambiente. Em seguida, o soro foi centrifugado nos mesmos tubos e, após a retirada do soro, este foi novamente centrifugado em tubos cônicos $^{1}$ de $15 \mathrm{ml}$. O soro foi inativado em banhomaria por 30 minutos à temperatura de $56^{\circ} \mathrm{C}$, separado em 3 grupos, filtrado, identificado e armazenado a $-20^{\circ} \mathrm{C}$.

Tratamento $1(\mathrm{~T} 1)=$ soro obtido de três éguas no primeiro dia do estro;

Tratamento $2(\mathrm{~T} 2)=$ soro obtido de três éguas 24-48h antes da ovulação;

Tratamento $3(\mathrm{~T} 3)=$ soro obtido de três éguas 24-48h após a ovulação;

Controle $(\mathrm{C})=$ soro de vaca em estro (SVE).

Todos estes estágios do estro foram determinados pela anamnese e palpação retal seguida de ultra-sonografia. O SVE utilizado no experimento foi o mesmo empregado nas rotinas do laboratório.

\section{Coleta dos ovários e seleção dos oócitos bovinos}

Os ovários foram coletados em frigoríficos localizados numa distância máxima de $30 \mathrm{~km}$ do laboratório onde foi efetuada a PIV e transportados em solução de $0,9 \%$ de $\mathrm{NaCl}$ acrescida de $50 \mathrm{UI} / \mathrm{ml}$ de Penicilina G-Potássica ${ }^{2}$, à temperatura ambiente $\left( \pm 25^{\circ} \mathrm{C}\right)$. Os folículos com diâmetro entre $2-8 \mathrm{~mm}$ foram puncionados com auxílio de uma bomba de vácuo. Os oócitos recuperados foram mantidos em líquido folicular até o momento da seleção, quando foram classificados de acordo com o critério de avaliação descrito por DeLoos [5], utilizando-se apenas oócitos de categoria 1 e 2.

\section{Maturação in vitro dos oócitos}

Após a escolha e seleção dos oócitos, estes foram distribuídos aleatoriamente em quatro grupos de 20 a 40 oócitos, lavados seis vezes com o meio de maturação, composto de TCM- $199^{3}$ modificado adicionado de $5,95 \mathrm{mg} / \mathrm{ml}$ de Hepes ${ }^{4}, 0,025 \mathrm{mg} / \mathrm{ml}$ de piruvato de sódio ${ }^{4}, 0,5 \mathrm{mg} / \mathrm{ml}$ de hormônio luteinizante 
bovino $^{5}(\mathrm{LHb}), 0,01 \mathrm{UI}$ de hormônio folículo estimulante recombinante humano ${ }^{6}(\mathrm{rFSHh}), 2,2 \mathrm{mg} / \mathrm{ml} \mathrm{de}$ bicarbonato de sódio ${ }^{4}$ e $10 \%$ soro de égua, do primeiro dia do estro (T1), de 24-48h antes da ovulação (T2), de 24-48h após a ovulação (T3) ou SVE (C ).

Após a lavagem, os oócitos foram colocados em placas de cultivo de quatro poços ${ }^{7}$ com $400 \mu l$ de meio de maturação e levados à estufa ${ }^{8}$ com $5 \%$ de $\mathrm{CO}_{2}$ à temperatura de $39^{\circ} \mathrm{C}$ e umidade saturada, por 22 a 24 horas.

\section{Fecundação in vitro dos oócitos}

Após a maturação, os oócitos foram transferidos para placas de quatro poços com $400 \mu 1$ de meio TALP-FERT, adicionado de $20 \mathrm{mg} / \mathrm{ml}$ de heparina ${ }^{4}, 6 \mathrm{mg} / \mathrm{ml}$ de $\mathrm{BSA}^{4}$ e $0,22 \mathrm{mg} / \mathrm{ml}$ de piruvato de sódio, previamente estabilizados na placa em estufa por duas horas.

Para a fecundação foi utilizado sêmen congelado de um "pool" de touros Bos taurus. O descongelamento foi realizado a $39^{\circ} \mathrm{C}$ por 20 segundos, sendo depositadas alíquotas de $100 \mu \mathrm{l}$ sob $1,0 \mathrm{ml}$ de meio TALP-SPERM acrescido de $6 \mathrm{mg} / \mathrm{ml}$ de BSA e $0,011 \mathrm{mg} / \mathrm{ml}$ de piruvato de sódio, em tubos cônicos de $15 \mathrm{ml}$. Estes foram mantidos a $39^{\circ} \mathrm{C}$ por uma hora em banho-maria para a migração ascendente ("swim up") dos espermatozóides. Após, o sobrenadante $(800 \mu 1)$ de cada tubo foi retirado e colocado em outro tubo e submetido à centrifugação por 10 minutos a $500 \mathrm{~g}$. $\mathrm{O}$ sedimento de cada tubo foi pipetado $( \pm 210 \mu 1)$, homogenizado e a dose inseminante foi de $1 \times 10^{6}$ espermatozóides $/ \mathrm{ml}$. O tempo de incubação conjunta dos oócitos e espermatozóides foi de 18 a 22 horas, sob atmosfera controlada, nas mesmas condições da maturação.

\section{Cultivo in vitro dos embriões}

Após a fecundação, os oócitos/zigotos foram transferidos para $400 \mu 1$ de meio SOF acrescido de $20 \mu 1 / \mathrm{ml}$ de aminoácidos essenciais, $10 \mu 1 / \mathrm{ml}$ de aminoácidos não-essenciais [19] + 5\% soro (T1, T2, $\mathrm{T} 3$ ou $\mathrm{C}$ ), conforme o tratamento, e submetidos a um processo de agitação mecânica para o desnudamento das células do cumulus oophorus. Logo após, os oócitos/zigotos foram lavados no meio de cultivo e transferidos para gotas de $400 \mu \mathrm{l}$ com meio SOF acrescido de $5 \%$ do respectivo soro, sob óleo para imediatamente serem submetidos ao cultivo em estufa à $39^{\circ} \mathrm{C}$, com $5 \%$ de $\mathrm{CO}_{2}$ e umidade saturada, por 8 dias.

No $2^{\circ}$ dia (D2) após o co-cultivo com os espermatozóides foi realizada a avaliação da clivagem, onde observou-se o número de zigotos com duas ou mais células. No $7^{\circ}$ dia (D7) após a fecundação foi efetuada a avaliação do índice de embriões que alcançaram o estágio de blastocisto (desde inicial até os mais avançados) e, 48 horas após, (D9) foi novamente avaliado o número de embriões no estágio de blastocisto, além da taxa de eclosão.

\section{Contagem do número de células}

Após a avaliação efetuada no $\mathrm{D} 9$, os embriões foram fixados em solução de paraformaldeído a $2 \%$, em PBS salino, para a realização da contagem do número de células. Os núcleos foram corados com o corante Hoechst ${ }^{4}$, sendo visualizados em microscópio de epifluorescência com filtro de excitação (365nm) e filtro de barreira (410nm).

\section{Avaliação in vivo}

Para a avaliação in vivo, 14 embriões foram submetidos ao transporte-cultivo individual por 8 horas, conforme o método preconizado por Brum [4].

\section{Análise estatística}

Foram realizadas 14 repetições compostas por quatro tratamentos com 20 a 40 oócitos cada. Para analisar o efeito dos tratamentos sobre a produção de embriões foi utilizado o teste do qui-quadrado, com um nível de significância de $5 \%$ e, para analisar o efeito do número de células, foi utilizado o teste de Tukey, sendo submetidos à transformação da raiz quadrada para normalizar os dados. Os dados foram analisados utilizando-se o pacote estatístico SAS [36]. 


\section{RESULTADOS}

Para a produção in vitro de embriões bovinos foram cultivados 1945 oócitos, os quais foram distribuídos aleatoriamente entre os tratamentos. A clivagem média foi de $78 \%$, o percentual de embriões em D7 foi de $19 \%$ e em D9 foi de $22 \%$. A taxa de eclosão em D9 foi de 5\% (Tabela 1).

$\mathrm{O}$ número médio de células dos blastocistos expandidos e eclodidos, dos diferentes tratamentos, estão apresentados na Tabela 2 e as taxas de prenhez na Tabela 3.

\section{DISCUSSÃO}

O soro é um componente de origem biológica utilizado em muitos protocolos de produção in vitro. Ele fornece nutrientes e fatores ainda pouco conhecidos, ou desconhecidos, os quais têm uma grande importância em todo o processo. Há, no entanto, sempre o risco da introdução de agentes patogênicos $[2,3,6,15,20,24,34,35,41]$. Kniazeff et al. [20] detectaram a presença de vírus como o da diarréia viral bovina (BVD), parainfluenza tipo 3, herpesvírus bovino tipo 1 (BHV-1), enterovírus bovino tipo 4, e

Tabela 1. Produção in vitro de embriões bovinos com soro de égua ou de vaca em estro

\begin{tabular}{|c|c|c|c|c|c|}
\hline Tratamento & $\begin{array}{c}\begin{array}{c}\text { Oócitos } \\
\text { n }\end{array} \\
\end{array}$ & $\begin{array}{c}\text { Clivagem } \\
\text { n (\%) }\end{array}$ & $\begin{array}{c}\text { D7 } \\
\text { n (\%) } \\
\end{array}$ & $\begin{array}{c}\text { D9 } \\
\text { n (\%) } \\
\end{array}$ & $\begin{array}{l}\begin{array}{l}\text { Eclosão } \\
\text { n (\%) }\end{array} \\
\end{array}$ \\
\hline $\mathrm{T} 1$ & 477 & $365(76,5)^{\mathrm{a}}$ & $100(21,0)^{\mathrm{a}}$ & $125(26,2)^{\mathrm{a}}$ & $47(9,85)^{\mathrm{a}}$ \\
\hline $\mathrm{T} 2$ & 477 & $374(78,4)^{\mathrm{a}}$ & $102(21,4)^{\mathrm{a}}$ & $116(24,3)^{\mathrm{a}}$ & $15(3,14)^{\mathrm{b}}$ \\
\hline $\mathrm{T} 3$ & 505 & $406(80,4)^{\mathrm{a}}$ & $100(19,8)^{\mathrm{a}}$ & $106(21,0)^{\mathrm{a} b}$ & $21(4,16)^{b}$ \\
\hline $\mathrm{C}$ & 486 & $364(74,9)^{\mathrm{a}}$ & $60(12,3)^{\mathrm{b}}$ & $80(16,5)^{b}$ & $20(4,12)^{b}$ \\
\hline Total & 1945 & $1509(77,6)$ & $362(18,6)$ & $427(21,9)$ & $103(5,30)$ \\
\hline \multicolumn{6}{|c|}{$\begin{array}{l}{ }^{a, b} \text { Letras diferentes, na mesma coluna, diferem signific } \\
\text { T1 = soro de égua obtido no primeiro dia do estro } \\
\text { T2 = soro de égua obtido } 24-48 \text { hs antes da ovulação } \\
\text { T3 = soro de égua obtido } 24-48 \text { hs após a ovulação } \\
\text { C = soro de vaca em estro }\end{array}$} \\
\hline
\end{tabular}

Tabela 2. Número médio de células, visualizadas em epifluorescência e coloração com Hoechst, de embriões bovinos produzidos in vitro, com soro de égua ou de vaca em estro

\begin{tabular}{|c|c|c|c|c|}
\hline \multirow{3}{*}{ Tratamento } & \multicolumn{4}{|c|}{ Número de Células } \\
\hline & \multicolumn{2}{|c|}{ Blastocistos Expandidos } & \multicolumn{2}{|c|}{ Blastocistos Eclodidos } \\
\hline & $\mathrm{n}$ & Média + dp & $\mathrm{n}$ & Média $+\mathrm{dp}$ \\
\hline $\mathrm{T} 1(\mathrm{n}=32)$ & 7 & $67,3^{a} \pm 19,4$ & 25 & $129,2^{\mathrm{a}} \pm 36,2$ \\
\hline $\mathrm{T} 2(\mathrm{n}=12)$ & 7 & $88,4^{a} \pm 16,7$ & 5 & $91,0^{\mathrm{ab}} \pm 37,2$ \\
\hline $\mathrm{T} 3(\mathrm{n}=12)$ & 5 & $64,0^{\mathrm{a}} \pm 17,9$ & 7 & $71,4^{b} \pm 21,0$ \\
\hline$C(n=19)$ & 10 & $81,2^{a} \pm 33,5$ & 9 & $136,3^{\mathrm{a}} \pm 62,9$ \\
\hline $\begin{array}{l}\mathrm{a}, \mathrm{b} \text { Letras diferentes, } \\
\mathrm{T} 1=\text { soro de égua o } \\
\mathrm{T} 2=\text { soro de égua ol } \\
\mathrm{T} 3=\text { soro de égua o } \\
\mathrm{C}=\text { soro de vaca em }\end{array}$ & $\begin{array}{l}\text { na, di } \\
\text { iro di } \\
\text { antes } \\
\text { após }\end{array}$ & $\begin{array}{l}\text { lo significativamen } \\
\text { ovulação } \\
\text { vulação }\end{array}$ & $0,05)$ & \\
\hline
\end{tabular}


Tabela 3. Taxas de prenhez aos 60 dias após a transferência de embriões bovinos produzidos in vitro, na presença de soro de égua ou de vaca em estro

\begin{tabular}{lcc}
\hline Tratamentos & $\begin{array}{c}\text { Transferidos } \\
\text { (n) }\end{array}$ & $\begin{array}{c}\text { Taxas de prenhez } \\
\text { n (\%) }\end{array}$ \\
\hline Soro eqüino do primeiro dia do estro (T1) & 5 & $2(40)$ \\
Soro eqüino de 24-48hs antes da ovulação (T2) & 4 & $1(25)$ \\
Soro eqüino de 24-48hs após a ovulação (T3) & 4 & $2(50)$ \\
Soro de vaca em estro (Controle) & 2 & $0(0)$ \\
\hline
\end{tabular}

outro não identificado, em $33 \%$ dos lotes de soro fetal bovino provenientes de 14 distribuidores. Grande parte destes lotes foram pré-testados e considerados livres pelo fabricante, no entanto, apresentavam viroses endógenas bovinas. Casos de infecção pelo vírus da BVD têm sido relatados como originários não dos embriões, mas do soro fetal bovino ou da albumina sérica bovina, que foram adicionados ao meio de cultivo. Apesar da melhoria dos métodos de coleta e processamento do soro que possibilitam a eliminação de contaminantes exógenos, certas viroses podem permanecer. Os métodos de inativação pelo calor ou radiação gama não são inteiramente eficazes na eliminação da contaminação vírica [31].

O porcentual médio de clivagem obtido na presente pesquisa é semelhante aos observados por outros autores $[4,7,8,22,42]$.

A média de embriões obtidos em D7 é semelhante aos resultados de outros autores que utilizaram meio sem a adição de vitaminas [42] e soro de vaca em estro $[4,8]$. Em experimento anterior, o soro de égua em estro foi testado por nossa equipe e os resultados obtidos foram superiores [7].

O índice médio de blastocistos em D9 foi superior aos índices observados em D7 indicando a evolução de alguns embriões em estágio menos avançado no sétimo dia e dos que já estavam no estágio de blastocisto, o que é esperado quando os mesmos possuem potencial de desenvolvimento.

A taxa média de embriões em D9 alcançada no presente experimento com o uso do soro de égua foi semelhante aos índices relatados por outros autores $[7,8,22]$ mas inferior aos resultados quando foi usado soro de vaca em estro [16].

Os protocolos de lavagem e tratamento com tripsina recomendados pelo manual da Sociedade Internacional de Transferência de Embriões [39] são eficientes para desinfecção de embriões coletados, embora não sirvam para embriões produzidos in vitro $[12,21,40,41]$. Isto ocorre, provavelmente, devido ao diâmetro dos poros da superfície da zona pelúcida (ZP) dos embriões produzidos in vitro, que permitem a penetração do BHV-1 e do BVDV na camada externa da ZP [44].

A utilização de um soro heterólogo pode ser uma importante alternativa para PIV de embriões bovinos, uma vez que sua eficiência seja comprovada. $\mathrm{O}$ soro eqüino é livre de atividade neutralizante de alguns vírus, como o da BVD e, por isto, é utilizado para pesquisa da transmissibilidade de patógenos nos processos de PIV [10,11,13,41].

Os resultados obtidos no presente estudo superaram as expectativas, pois a PIV de embriões, nos tratamentos nos quais foi utilizado o soro de égua, foi de 57 a $62 \%$ superior ao grupo controle, cujo soro utilizado foi o de vaca em estro. Estes resultados podem ser atribuídos aos fatores inespecíficos encontrados no soro. Figueiró et al.[7] utilizaram como fonte protéica o soro de égua em estro e não verificaram diferença estatística entre os grupos que usaram este soro e o grupo controle que utilizava soro de vaca em estro como fonte protéica, tendo $30 \%$ de blastocistos em D7. Outro aspecto que deve ser considerado são as variações individuais existentes entre indivíduos da mesma espécie e, por isso, é importante, em laboratórios que trabalhem com PIV, a análise de várias partidas de soro de diferentes animais e em diferentes misturas. Além disto, as técnicas de preparo deste soro devem ser seguidas criteriosamente para que se tenha a padronização do soro. 
O número de células dos embriões PIV pode ser considerado um bom indicador da viabilidade dos mesmos [14]. Existe uma grande variabilidade nas médias do número de células dos embriões PIV, sendo reportados, para blastocistos expandidos, números de 67 [18], 94 [4], 105 [23] e 133 células [1]. Para blastocistos eclodidos os valores variam de 93 a 204 $[4,23,45]$. Os valores observados no presente experimento se equiparam ou até superam os descritos na literatura. A diferença estatística encontrada na média do número de células dos blastocistos eclodidos entre T1 (129) e C (136) sobre T3 (71) é explicada, provavelmente, pelo baixo número de embriões analisados e não por uma diferença na qualidade dos mesmos.

Outro método para a avaliação da viabilidade dos embriões PIV é a taxa de prenhez e o nascimento de produtos saudáveis como o que ocorreu neste experimento (Tabela 3), apesar do número reduzido de embriões transferidos. O pequeno número de animais utilizados como receptoras e também as condições corporais destas tiveram uma influência negativa sobre a taxa de prenhez, sendo que se espera após transferência de embriões PIV uma taxa de prenhez de 20 a $40 \%$.

\section{CONCLUSÕES}

A utilização de soro de égua para a PIV de embriões bovinos é possível, pois os embriões resultantes têm semelhante viabilidade, tanto in vitro como in vivo, quando comparados com embriões produzidos com soro de vaca. Para maior produção de blastocistos, o soro deve ser coletado, preferencialmente, no primeiro dia do estro das éguas.

\section{AGRADECIMENTOS}

Os autores agradecem ao "National Hormone and Pituitary Program"- Baltimore, MD, USA, pela gentil cedência do LH utilizado nesta pesquisa. Agradecem também ao Dr. Neimar Corrêa Severo da PECPLAN-ABS-Rosário do Sul, RS, pelo fornecimento do sêmen utilizado, ao Frigorífico Silva que cedeu os ovários bovinos, ao Setor de Suínos da UFRGS pela utilização do microscópio de epifluorescência e de suas instalações e à Cabanha Santo Isidro pela cedência das receptoras.

\section{NOTAS INFORMATIVAS}

${ }^{1}$ Corning ${ }^{\circledR}$, Corning glass works, Corning NY, 14831, USA.

${ }^{2}$ Sigma Chemical CO. - P.O. Box 4508, MO, USA.

${ }^{3}$ Cultilab Ltda. - Rua Maria Monteiro, 177 Cambuí 13025-150 Campinas, SP.

${ }^{4}$ Sigma Chemical CO. - P.O. Box 4508, MO, USA.

${ }^{5}$ Serono Pharma S.p.A - 70123, Bari, Itália

${ }^{6}$ National Hormone and Pituitary Program - Baltimore, MD, USA

${ }^{7}$ Nunclon, Nunc Brand Products, Denmark, Cat. $\mathrm{n}^{\mathrm{o}}$ 176740.

${ }^{8}$ W.C. Heraeus GmbM. Postfach 1553 D-6459 Hanau 1, Alemanha.

\section{REFERÊNCIAS}

1 Avery B. \& Quetglas D. 1996. Evolution of day 8 and 9 in vitro derived bovine blastocysts, fertilized with two different bulls. Theriogenology. 45: 213.

2 Bolin S.R., Matthews P.J. \& Ridpath J.F. 1991. Methods for detection and frequency of contamination of fetal calf serum with bovine viral diarrhea virus and antibodies against bovine viral diarrhea virus. Journal of Veterinary Diagnostic Investigation. 3: 199-203.

3 Brock K.V. 1998. Controle de qualidade para materiais de origem animal usados em produção e transferência de embriões. In: Stringfellow D.A. \& Seidel S.M. (Eds). Manual da Sociedade Internacional de Transferência de Embriões. São Paulo: IETS, pp.141-146.

4 Brum D.S., Bernardi M.L., Palma G.A., Leivas F.G., Silva C.A.M \& Rubin M.I.B. 2001. Transporte-cultivo de embriões bovinos produzidos in vitro. Arquivos da Faculdade de Veterinária UFRGS. 28: 36-50.

5 DeLoss F., Vanvliet C., Vanmaurik P. \& Kruip Th.A.M. 1989. Morphology of imature bovine oocytes. Gamete Research. 24: 197-204. 
Figueiró G.M., Fialho S.S., Brum S.D., Pasin M., Rauber L.P., Bernardi M.L., Mezzalira A., Rubin M.I.B. \& Silva C.A.M. 2002. Produção in vitro de embriões bovinos com soro de égua em diferentes fases do estro. Acta Scientiae Veterinariae. 30: 1- 8.

6 Erickson G.A., Bolin S.R. \& Landgraf J.G. 1991. Viral contamination of fetal bovine serum used for tissue culture: risks and concerns. Developmental Biology Standard. 75: 173-175.

7 Figueiró G.M., Mezzalira A., Rauber L.P., Leivas F.G., Almeida N.V., Rubin M.I.B. \& Silva C.A.M. 2000. O soro eqüino na PIV de embriões bovinos: II. Uma análise da adição de FSH e LH. Arquivos da Faculdade de Veterinária UFRGS. 28(supl): 259.

8 Forell F., Oliveira A.T.D. \& Rodrigues J.L. 2000. Produção in vitro de embriões bovinos adicionando glicose em diferentes momentos do cultivo. Arquivos da Faculdade de Veterinária UFRGS. 28 (supl): 267.

9 Ghasemzadeh-Nava H. \& Tajik P. 2000. In vitro maturation of ovine follicular oocytes in different concentrations of fetal calf serum and estrous sheep serum. Theriogenology. 53: 453.

10 Givens M.D., Galik P.K., Ridell K.P., Brock K.V. \& Stringfellow D.A. 1999. Bovine viral diarrhea virus associated with IVF embryos does not infect susceptible cells. Theriogenology. 51:271

11 Givens M.D., Galik P.K., Riddell K.V., Brock K.V. \& Stringfellow D.A. 1999. Quantity and infectivity of embryo-associated bovine viral diarrhea virus and antiviral influence of a blastocyst impede in vitro infection of uterine tubal cells. Theriogenology. 52: 887-900.

12 Givens M.D., Galik P.K., Ridell K.P., Brock K.V. \& Stringefellow D.A. 2000. Potential for noncytopathic strains of bovine viral diarrhea virus to associate with IVF embryos and remain infective. Theriogenology. 53: 319.

13 Givens M.D., Galik P.K., Riddell K.P. \& Stringfellow D.A. 1998. Bovine viral diarrhea virus was not detected in association with virally exposed IVF bovine embryos. Theriogenology. 49: 252.

14 Gordon I. 1994. Laboratory Production of Cattle Embryo. CAB International, University Press, Cambridge, $640 \mathrm{p}$.

15 Guerin B., Nibart M., Marquant-Leguienne B. \& Humbolt P. 1997. Sanitary risks related to embryo transfer in domestic animals. Theriogenology. 47: 33-42.

16 Holm P., Booth P.J., Schmidt M.H., Greve T. \& Callesen H. 1999. High bovine blastocyst development in a static in vitro production system using SOFaa medium supplemented with sodium citrate and myo-inositol with or without serum-proteins. Theriogenology. 52: 683-700.
17 Iwasaki T., Kimura E. \& Totsukawa K. 1999. Studies on a chemically defined medium for in vitro culture of in vitro matured and fertilized porcine oocytes. Theriogenology. 51: 709-720.

18 Jiang H.S., Wang W.L., Lu K.H., Gordon I. \& Polge C. 1992. Examination of cell numbers of blastocysts derived from IVM, IF and IVC bovine follicular oocytes. Theriogenology. 37: 229.

19 Kim J.H., Niwa K., Lim J.M. \& Okuda K. 1993. Effects of phosphate, energy substrates, and amino acids development of in vitro-matured, in vitro-fertilized bovine oocytes in a chemically defined, protein-free culture medium. Biology of Reproduction. 48: 1320-1325.

20 Kniazeff A.J., Wopschall L.J., Hopps H.E. \& Morris C.S. 1975. Detection of bovine viruses in fetal bovine serum used in cell culture. In vitro. 11: 400-403.

21 Langston N.L., Stringfellow D.A., Galik P.K. \& Garret G.E. 1999. Failure to wash bluetongue virus from bovine IVF embryos. Theriogenology. 51: 273.

22 Lehmkuhl R.C., Mezzalira A., Vieira A.D., Silva C.A.M. \& Rubin M.I.B. 2000. Desenvolvimento de oócitos bovinos mantidos em líquido folicular e submetidos a FIV. Arquivos da Faculdade de Veterinária UFRGS. 27 (supl): 276.

23 Lonergan P., Fair T. \& Gordon I. 1992. Effect of time of transfer to granulosa cell monolayer and cell-stage at 48 hours post-insemination on bovine oocyte development following IVM/IVF/IVC. In: Proceedings of the $8^{\text {th }}$ Conference of the European Embryo Transfer Association (Lyon, France). p.178.

24 Long C.R., Dobrinsky J.R. \& Johnson, L.A. 1999. In vitro production of pig embryos: comparisons of culture media and boars. Theriogenology. 51: 1375-1390.

25 Lu K.H., Gordon I., Chen H..B. \& Mcgovern H. 1987. In vitro culture of early bovine embryos derived from in vitro fertilization of follicular oocytes matured in vitro. In: : Proceedings of the $3^{\text {rd }}$ Conference of the European Embryo Transfer Association (Lyon, France). p.70.

26 Lu K.H., Gordon, I., Chen H.B., Gallagher M. \& Mcgovern H. 1988. Birth of twins after transfer of cattle embryos produced by in vitro techniques. Veterinary Record. 122: 539-540.

27 Marquant-Leguienne B. \& Humblot P. 1998. Pratical measures to improve in vitro blastocyst production in the bovine. Theriogenology. 49: 3-11.

28 Mezzalira A., Barichello E.M.M.R. \& Rubin M.I.B. 1990. Avaliação de diferentes fontes protéicas no cultivo 
Figueiró G.M., Fialho S.S., Brum S.D., Pasin M., Rauber L.P., Bernardi M.L., Mezzalira A., Rubin M.I.B. \& Silva C.A.M. 2002. Produção in vitro de embriões bovinos com soro de égua em diferentes fases do estro. Acta Scientiae Veterinariae.30: 1-8.

de mórulas Mus musculus em PBS. In: VReunião Anual da SBTE ( Curitiba, Brasil). pp.81-82.

29 Mezzalira A., Barichello E.M.M.R. \& Rubin M.I.B. 1990. Cultivo de embriões Mus musculus com soro eqüino. In: VReunião Anual da SBTE (Curitiba, Brasil). pp.83-84.

30 Mezzalira A., Barichello E.M.M.R. \& Rubin M.I.B. 1990. Cultivo de mórulas Mus musculus em meio de WHITTEN, com diferentes fontes protéicas. In: $V$ Reunião Anual da SBTE (Curitiba, Brasil). pp.86-87.

31 Palaz A.T. \& Del Campo M. 1995. Cryopreservation of mammalian oocytes and embryos: Recent advances. In: Anais do I Seminario Internacional de Transferencia de Embriones - Biotecnologia y Tecnologia Avanzadas (Montevideo, Uruguay). pp.7885.

32 Pinyopummintr T. \& Bavister B.D. 1991. In vitromatured/in vitro-fertilized bovine oocytes can develop into morulae/blastocysts in chemically defined, protein-free culture media. Biology of Reproduction. 45: 736-742.

33 Ptak G., Dattena M., Loi P., Tischner M \& Cappai P. 1999. Ovum pick-up in sheep: efficiency of in vitro embryo production, vitrification and birth of offspring. Theriogenology. 52: 1105-1114.

34 Roehe P.M., Oliveira E.A.S., Oliveira L.G. \& Muñoz J.C.P. 1998. A situação do vírus da diarréia viral bovina no país. In: Simpósio Internacional sobre herpesvirus bovinos (Tipo 1 e 5) e vírus da diarréia viral bovina (BVDV) (Santa Maria, Brasil). pp.39-48.

35 Rossi C.R., Bridgman B.S. \& Kiesel G.K. 1980. Viral contamination of bovine fetal lung cultures and bovine fetal serum. American Journal of Veterinary Research. 41: 680-168.

36 SAS Institute (Cary NC). 1990. SAS user's guide: Statistical Analysis System, Release 6.12.2576p.

37 Serbian J.M., Scanlon P.F. \& Gordon I. 1968. Culture of fertilized cattle eggs. Journal of Agriculture Science. 70: 183-185.

38 Sreenan J.M. \& Scanlon P.F. 1968. Continued cleavage of fertilized bovine ova in the rabbit. Nature. 217 : 867.

39 Stringfellow D.A. 1998. Recomendações para o manuseio sanitário de embriões obtidos in vivo. In: Stringfellow D.A. \& Seidel S.M. (Eds). Manual da Sociedade Internacional de Transferência de Embriões. São Paulo: IETS, pp.83-88.
40 Stringfellow D.A., Riddell K.P., Galik P.K., Damiani, P., Bishop M.D. \& Wright J.C 2000. Quality controls for bovine viral diarrhea virus-free IVF embryos. Theriogenology. 53: 827-839.

41 Stringefellow D.A., Riddell K.P., Galik P.K., Damiani P. \& Wright J.C. 1999. Quality controls for bovine viral diarrhea virus-free IVF embryos. Theriogenology. 51: 275.

42 Takahashi Y. \& First N.L. 1992. In vitro development of bovine one-cell embryos: influence of glucose, lactate, pyruvate, amino acids and vitamins. Theriogenology. 37: 963-978.

43 Thompson J.G. 1999. Cultura in vitro de embriões bovinos: novas técnicas e conseqüências póstransferência. Arquivos da Faculdade de Veterinária UFRGS. 27 (supl): 133-146.

44 Vanroose G., Nauwynck H., Van Soom A., Ysebaert M., Charlier G., Van Oostveldt P. \& de Kruif A. 1999. Why is the zona pellucida of in vitro-produced embryos an efficient barrier for viral infection? A scanning electron and confocal laser scanning microscopic study. Theriogenology. 51: 276.

45 Van Soom A., Vanroose G., Bols P.E.J., Boerjan M.L., Ysebaert M.T. \& de Kruif A. 1996. Timing allocation and number of inner cells in vitro produced bovine embryos cultured of oocytes. Theriogenology. 45: 193.

46 Willis P., Fayrer-Hosken R.A. \& Caudle A.B. 1990. Effect of serum on in vitro maturation of equine oocytes. Theriogenology. 33: 345 . 